\title{
Participation Motivation Questionnaire: tradução e validação para uso em atletas-jovens brasileiros
}

CDD. 20.ed. 796.011

796.031

796.073

\author{
Dartagnan Pinto GUEDES* \\ José Evaristo SILVÉRIO NETTO* \\ *Departamento de \\ Educação Física e \\ Esporte, Universidade \\ Norte do Paraná.
}

\section{Resumo}

Os objetivos do estudo foram traduzir para o idioma português, realizar a adaptação transcultural e identificar as propriedades psicométricas para atletas-jovens brasileiros do Participation Motivation Questionnaire (PMQ). A versão original foi traduzida de acordo com recomendações internacionais. Um comitê de juizes foi formado para analisar as versões traduzidas do questionário. 0 comitê utilizou como critério de análise as equivalências semântica, idiomática, cultural e conceitual. A versão final do questionário traduzido foi administrada em uma amostra de 1517 atletas-jovens (714 moças e 803 rapazes) com idades entre 12 e 18 anos. Para identificar as propriedades psicométricas foi realizada análise fatorial confirmatória com rotação Varimax e, na sequência, para análise da consistência interna de cada fator associado à motivação para a prática de esporte, foi empregado coeficiente alfa de Cronbach. Após discretas modificações apontadas no processo de tradução, o comitê de juízes considerou que a versão para o idioma português do PMO apresentou equivalências semântica, idiomática, cultural e conceitual. A análise fatorial confirmou a estrutura de oito fatores originalmente proposta, explicando $67 \%$ da variância total com satisfatórios valores de consistência interna. 0 alfa de Cronbach apresentou coeficientes entre 0,543 e 0,827. Concluindo, a tradução, a adaptação transcultural e as qualidades psicométricas do PMQ foram satisfatórias, o que viabiliza sua aplicação em futuros estudos no Brasil.

Palavras-chave: PMO; Questionário; Psicometria; Treino esportivo; Adolescentes; Brasil.

\section{Introdução}

A motivação para a prática de esporte em idades jovens é uma das principais temáticas que vem atraindo a atenção de pesquisadores e profissionais da área. Uma amostra disso são as diversas aproximações teóricas sugeridas recentemente para tentar explicar a conduta motivacional no contexto esportivo $^{1-3}$ e o esforço direcionado ao desenvolvimento e à validação de instrumentos para identificar e dimensionar os motivos que levam os jovens a optarem por iniciar, permanecer, ou ao contrário, abandonar a prática de esporte ${ }^{4-6}$.

Nessa perspectiva, os motivos ou razóes que levam os jovens a se envolverem com a prática de esporte são identificados e dimensionados mediante a utilização de questionários específicos, entre os quais, o de maior destaque na literatura especializada é o Participation Motivation Questionnaire - $\mathrm{PMQ}^{7}$, contribuindo de maneira decisiva para a realização de comparações mais efetivas e homogenias entre diferentes estudos. O PMQ foi concebido com 30 itens equivalentes ao elenco de possíveis motivos que possam levar os atletas-jovens a praticar esportes, agrupados em oito fatores de motivação: a) reconhecimento social; b) atividade de grupo; c) aptidão física; d) emoção; e) competição; f) competência técnica; g) afiliação; e h) diversão. Em seu delineamento o respondente indica o grau de importância que mais se aplica para a sua pratica de esporte, mediante escala de medida tipo Lickert de três pontos. Contudo, na sequência, para oferecer maior capacidade discriminatória aos motivos para a prática de esporte, $\mathrm{DWYER}^{8}$ realizou adaptação na escala de medida original, ampliando as opçôes de valores para cinco pontos $(1=$ "nada importante" a 5 = "muito importante").

Pelo fato de o PMQ ter sido desenvolvido em idioma inglês, a princípio a maioria dos estudos 
referidos na literatura vinha sendo realizados em países anglo-saxônicos. No entanto, mais recentemente pesquisadores de países de outros idiomas se interessaram em traduzir e validar o PMQ, o que permitiu a expansão de sua utilização para outras culturas $^{9-16}$.

Especificamente em idioma português são identificadas duas tentativas de tradução e validação do PMQ para aplicação em populações de atletasjovens. Uma primeira tentativa envolveu o idioma português europeu e recebeu nova denominação: Questionário de Motivação de Actividades Desportivas - QMAD9. Neste caso, foram mantidos na versão traduzida os 30 itens propostos inicialmente; porém, reagrupados em somente sete fatores de motivação e mediante disposição acentuadamente diferente da versão original. Porém, estudos posteriores apontaram limitaçóes metodológicas na definição do $Q M A D$ que podem comprometer sua aplicação ${ }^{17}$. Com relação à amostra envolvida no estudo que propôs o $Q M A D$, foi selecionada quantidade insuficiente de sujeitos (90 moças e 85 rapazes) para que se possa alcançar ajuste do modelo fatorial estatisticamente adequado com 30 itens. Somado a isso, não ocorreram eventuais re-especificaçōes na busca de melhor adequação entre itens e fatores; assim, sólidos critérios conceituais disponibilizados no campo de motivação cederam preferência aos comprometidos achados estatísticos. Ainda, pelo fato do $P M Q$ tratar-se de um instrumento que contém extensa lista de diferentes motivos para a prática de esporte em idades jovens expressos em frases, sua tradução para outro idioma, mesmo um idioma bastante similar ao utilizado no Brasil como é o caso do português europeu, pode comportar

\section{Método}

Os protocolos de tradução e adaptação transcultural acompanharam procedimentos sugeridos por GUILLEMIN et al. ${ }^{19}$. A tradução inicial do idioma original (inglês) para o português foi realizada de maneira independente por dois pesquisadores com entendimento detalhado do $P M Q$. Os dois pesquisadores tinham como idioma nativo o português e amplo domínio do idioma inglês, com experiência em traduçôes de textos acadêmicos. Além da tradução, foi solicitado que registrassem expressōes que poderiam oferecer dúbia interpretação.

Um grupo bilíngue formado por três pesquisadores da área do esporte comparou os textos traduzidos, algumas diferenças de expressões idiomáticas e de matrizes provenientes de diferenças culturais.

$\mathrm{Na}$ sequência, para utilização no Brasil, GAYA e CARDOSO $^{18}$ procuraram idealizar nova adaptação do $P M Q$, utilizando como referência a versão já traduzida para o idioma português europeu do $Q M A D$. Para tanto, baseando-se em estudo-piloto com abordagem exploratória envolvendo jovens de sete a 14 anos de idade, em que 110 sujeitos foram convidados a descrever os cinco principais motivos que os levavam a praticar esporte, reduziram arbitrariamente a quantidade de itens de 30 para 19, excluindo itens originais e inserindo novos itens. Esta versão recebeu denominação de Inventário de Motivação para a Prática Desportiva - IMPD e abriga os itens em três fatores de motivação: a) competência esportiva; b) amizade/lazer; e c) saúde. Mediante análise mais detalhada identifica-se que quantidade significativa de itens inseridos no IMPD não esta presente na versão original do $P M Q$ e seus conteúdos são claramente voltados para crianças em idades mais precoces. Logo, parece mais lógico assumir que o IMPD não seja uma tradução/adaptação do $P M Q$, mas sim, instrumento inédito direcionado a identificar os motivos que levam crianças ainda não envolvidas em programas sistematizados de treino a praticar esporte.

Desse modo, diante da necessidade de disponibilizar instrumento de medida que possa ser empregado para identificar, dimensionar e ordenar os motivos voltados à prática de esporte em idades jovens apropriados à cultura brasileira, os objetivos do estudo foram traduzir para o idioma português, realizar a adaptação transcultural e identificar as propriedades psicométricas para atletas-jovens brasileiros do $P M Q$. uniformizando o uso de expressões divergentes, e foi produzida uma versão única do questionário que sintetizou as duas versōes anteriores. Em seguida, ocorreu a retrotradução do questionário por dois outros tradutores de maneira independente. Os tradutores escolhidos para essa etapa tinham como idioma nativo o inglês, domínio do idioma português e atuação como docente universitário em Instituição brasileira. Solicitou-se aos tradutores que registrassem expressōes que pudessem gerar dúvidas no processo de retrotradução. O grupo bilíngue comparou ambos os textos retrotraduzidos, produzindo versão única. 
Um comitê analisou o processo de tradução e os resultados alcançados nas etapas anteriores. $\mathrm{O}$ comitê foi formado por nove membros, incluindo os autores do estudo, tradutores que participaram do processo de tradução/retrotradução e três docentes universitários da área do esporte, todos bilíngue inglês-português. $\mathrm{O}$ comitê realizou revisão das sete versões do $P M Q$ disponível: versão original em língua inglesa, duas versôes traduzidas para o idioma português, versão síntese de ambas as traduções para o idioma português, duas versões de retrotradução e versão síntese de ambas as retrotraduções.

O comitê realizou apreciação dos tipos de equivalências entre o instrumento original e a versão no idioma português. Os membros receberam orientações por escrito sobre o objetivo do estudo e as definiçōes adotadas para as equivalências. Cada um respondeu individualmente a um formulário de análise que comparava cada item do instrumento original, da versão síntese traduzida para o idioma português e da versão síntese de retrotradução, em relação às equivalências semântica, idiomática, cultural e conceitual. $\mathrm{O}$ formulário de análise foi estruturado mediante escala diferencial com alternativas discretas: "inalterada", "pouco alterada", "muito alterada" e "completamente alterada".

Próxima etapa do estudo foi realizar testagem do PMQ traduzido para o português, com intuito de identificar suas propriedades psicométricas. Para tanto, o PMQ foi aplicado em uma amostra de atletas-jovens participantes dos Jogos da Juventude do Paraná no ano 2009. Para seleção da amostra utilizou-se método não probabilístico casual. Para tanto, previamente ao início das competiçôes, todos os técnicos e dirigentes participantes dos Jogos foram contatados e informados quanto à natureza, aos objetivos do estudo e ao princípio de sigilo. Na sequência, foi solicitado autorização para contatar e convidar os atletas-jovens para participarem do estudo. Mediante confirmação pelo Termo de Consentimento Livre e Esclarecido, 1517 atletas-jovens (714 moças e 803 rapazes), com idades entre 12 e 18 anos, concordaram em participar do estudo, o que representou por volta de 30\% do universo de participantes da competição.

O PMQ foi aplicado em um único momento, individualmente para cada atleta-jovem e por um único pesquisador. Procurou-se evitar a aplicação do questionário em situações em que os atletas-jovens pudessem estar imerso em estresse pré ou póscompetição. Neste caso, utilizaram-se os momentos em que os atletas-jovens não se encontravam em ambiente de competição ou quando eram tão-somente expectadores das competições. Os atletas-jovens receberam o questionário com instruções e recomendaçôes para o seu preenchimento, não sendo estabelecido limite de tempo para o seu término. Eventuais dúvidas manifestadas pelos respondentes foram prontamente esclarecidas pelo pesquisador que acompanhava a coleta dos dados.

Para identificação das propriedades psicométricas do $P M Q$ foram empregados dois procedimentos estatísticos. Para análise e confirmação da estrutura fatorial proposta em sua versão original foi empregada a análise fatorial confirmatória, por intermédio da técnica de componentes principais com rotação ortogonal (Varimax) e normalização de Kaiser, seguindo um critério de exclusão daqueles itens com carga fatorial inferior a 0,40 ou que estivessem representados em mais de um fator. Para investigação quanto à consistência interna foram empregados os cálculos de $\alpha$ de Cronbach para cada um dos itens que compóe o instrumento. Os dados foram tratados utilizando-se o pacote estatístico computadorizado SPSS - versão 17.0. O estudo foi aprovado pelo Comitê de Ética em Pesquisa Envolvendo Seres Humanos da Universidade Estadual de Londrina, Paraná (Parecer 086/08).

\section{Resultados}

Detalhamento quanto ao gênero, à idade, à classe econômica familiar e ao histórico de treino dos atletas-jovens selecionados para o estudo esta descrito na TABELA 1. Dos 1517 atletas-jovens envolvidos no estudo, $47 \%$ eram moças e, considerando ambos os sexos, $49,3 \%$ deles tinham entre 15 e 16 anos e proporção similar se distribuiu em idades $\leq 14$ anos e $\geq 17$ anos. Contudo, identificou-se maior proporção de rapazes (30,9\%), em comparação com as moças $(18,5 \%)$, em idades $\geq 17$ anos. No que se refere à classe econômica familiar, com proporções similares em ambos os gêneros, 25,2\% foram categorizados na classe A (maior nível econômico) e 2,8\% na classe D (menor nível econômico). Nas classes intermediárias B e C foram identificados 48,7\% e 23,3\% dos atletas-jovens selecionados na amostra.

No que se refere ao histórico de treino, proporçôes similares de moças $(28,7 \%)$ e rapazes $(31,3 \%)$ 
iniciaram os treinos em idades $\leq 9$ anos; no entanto, mais elevada proporção de rapazes iniciaram os treinos em idades $\geq 14$ anos (23,4\% versus 13,7\%). Quanto à experiência de treino, identificou-se menor tempo de treino entre as moças, sendo que, 30,8\% delas apontaram ter $\leq 2$ anos de treino em comparação com $18,1 \%$ dos rapazes. Com experiência de treino $\geq 7$ anos observou-se $15,2 \%$ das moças e $25,5 \%$ dos rapazes. De maneira similar em ambos os sexos, maior proporção de atletas-jovens reunidos na amostra
$(44,6 \%)$ treinavam $\geq 5$ vezes/semana e $14,1 \%$ relataram frequência de treino $\leq 2$ vezes/semana. Com relação à duração das sessões de treino, $68,3 \%$ apontaram treinar 1-2 horas/sessão e 22,6\% 3-4 horas/sessão. Constatou-se predomínio de treino em modalidades coletivas $(61,5 \%)$ e $84,7 \%$ dos atletasjovens demonstraram experiência em competiçóes de abrangência regional e estadual. Do restante, 10,9\% e 4,4\% relataram experiência em competições nacionais e internacionais, respectivamente.

TABELA 1 - Indicadores sociodemográficos e histórico de treinamento da amostra de atletas-jovens analisados no estudo.

\begin{tabular}{|c|c|c|c|c|}
\hline & & $\begin{array}{c}\text { Moças } \\
(\mathrm{n}=714)\end{array}$ & $\begin{array}{l}\text { Rapazes } \\
(\mathbf{n}=\mathbf{8 0 3})\end{array}$ & $\begin{array}{c}\text { Ambos os sexos } \\
\qquad(\mathrm{n}=1517)\end{array}$ \\
\hline \multirow[t]{3}{*}{ Idade } & $\leq 14$ anos & $244(34,0 \%)$ & $145(18,1 \%)$ & $389(25,6 \%)$ \\
\hline & $15-16$ anos & $339(47,5 \%)$ & $410(51,0 \%)$ & $749(49,3 \%)$ \\
\hline & $\geq 17$ anos & $131(18,5 \%)$ & $248(30,9 \%)$ & $379(25,1 \%)$ \\
\hline \multirow[t]{4}{*}{ Classe econômica familiar } & Classe A (Maior) & $183(25,6 \%)$ & $200(24,9 \%)$ & $383(25,2 \%)$ \\
\hline & Classe B & $334(46,8 \%)$ & $405(50,4 \%)$ & $739(48,7 \%)$ \\
\hline & Classe C & $173(24,2 \%)$ & $180(22,4 \%)$ & $353(23,3 \%)$ \\
\hline & Classes D (Menor) & $24(3,4 \%)$ & $18(2,3 \%)$ & $42(2,8 \%)$ \\
\hline \multirow[t]{4}{*}{ Idade de inicio do treino } & $\leq 9$ anos & $205(28,7 \%)$ & $251(31,3 \%)$ & $456(30,1 \%)$ \\
\hline & $10-11$ anos & $210(29,4 \%)$ & $168(20,9 \%)$ & $378(24,9 \%)$ \\
\hline & $12-13$ anos & $201(28,2 \%)$ & $196(24,4 \%)$ & $397(26,2 \%)$ \\
\hline & $\geq 14$ anos & $98(13,7 \%)$ & $188(23,4 \%)$ & $286(18,8 \%)$ \\
\hline \multirow[t]{4}{*}{ Tempo de treino } & $\leq 2$ anos & $220(30,8 \%)$ & $145(18,1 \%)$ & $365(24,1 \%)$ \\
\hline & $3-4$ anos & $203(28,4 \%)$ & $191(23,8 \%)$ & $394(26,0 \%)$ \\
\hline & $5-6$ anos & $183(25,6 \%)$ & $262(32,6 \%)$ & $445(29,3 \%)$ \\
\hline & $\geq 7$ anos & $108(15,2 \%)$ & $205(25,5 \%)$ & $313(20,6 \%)$ \\
\hline \multirow[t]{3}{*}{ Frequência de treino } & $\leq 2$ vezes $/$ semana & $115(16,1 \%)$ & $98(12,2 \%)$ & $213(14,1 \%)$ \\
\hline & 3 - 4 vezes/semana & $290(40,6 \%)$ & $337(42,0 \%)$ & $627(41,3 \%)$ \\
\hline & $\geq 5$ vezes $/$ semana & $309(43,3 \%)$ & $368(45,8 \%)$ & $677(44,6 \%)$ \\
\hline \multirow[t]{4}{*}{ Duração de treino } & $\leq 1$ hora/treino & $55(7,7 \%)$ & $49(6,1 \%)$ & $104(6,9 \%)$ \\
\hline & 1 - 2 horas/treino & $460(64,4 \%)$ & $576(71,7 \%)$ & $1036(68,3 \%)$ \\
\hline & $3-4$ horas/treino & $180(25,2 \%)$ & $163(20,3 \%)$ & $343(22,6 \%)$ \\
\hline & $\geq 5$ horas $/$ treino & $19(2,7 \%)$ & $15(1,9 \%)$ & $34(2,2 \%)$ \\
\hline \multirow[t]{2}{*}{ Modalidade esportiva } & Individual & $286(40,1 \%)$ & $298(37,1 \%)$ & $584(38,5 \%)$ \\
\hline & Coletiva & $428(59,9 \%)$ & $505(62,9 \%)$ & $933(61,5 \%)$ \\
\hline \multirow[t]{4}{*}{ Nível de competição } & Internacional & $21(2,9 \%)$ & $45(5,6 \%)$ & $66(4,4 \%)$ \\
\hline & Nacional & $63(8,8 \%)$ & $103(12,8 \%)$ & $166(10,9 \%)$ \\
\hline & Estadual & $293(41,1 \%)$ & $329(41,0 \%)$ & $622(41,0 \%)$ \\
\hline & Regional/Municipal & $337(47,2 \%)$ & $326(40,6 \%)$ & $663(43,7 \%)$ \\
\hline
\end{tabular}


Discretas divergências no uso de expressões foram observadas nas etapas do processo de tradução. As eventuais divergências foram discutidas no comitê de análise e prevaleceram as expressóes de mais fácil compreensão e de uso frequente entre os atletas-jovens, para facilitar o entendimento. Dos 30 itens que compõe o PMQ, em 24 deles (80\%) os membros do comitê de análise apontaram como "inalterada" as equivalências semântica, idiomática, cultural e conceitual. Nos seis restantes (20\%), os membros do comitê apontaram "pouco alterada" pelo menos uma das equivalências. Nenhum item da versão traduzida do $P M Q$ apresentou as opções "muito alterada" ou "completamente alterada" assinaladas em comparação com a versão original.

Por ocasiāo da aplicação experimental do instrumento traduzido no grupo-alvo, os atletas-jovens não manifestaram maior dificuldade quanto à clareza e ao entendimento das expressões empregadas. Contudo, a maioria deles sugeriu suprimir as expressóes "Eu quero" e "Eu gosto" que originalmente iniciava a frase de cada item, para evitar a monotonia de repetir constantemente expressões idênticas e tornar a leitura mais imediata para o preenchimento do PMQ. Em vista disso, o comitê de análise optou por modificar a tradução "ipsis literis" da versão original do instrumento, e o conjunto dos 30 itens passou a ser precedido pelo enunciado "Eu pratico esporte para...". Neste caso, a grafia de cada item passou a ser um complemento da afirmação inicial, em que o respondente assinala na escala de medida o grau de importância para sua decisão em praticar esporte. Versão traduzida do $P M Q$ pode ser conferida no ANEXO I.

Quanto às propriedades psicométricas, considerouse, inicialmente, a adequação para se realizar a análise fatorial confirmatória com o conjunto dos 30 itens que compõe o $P M Q$. Para tanto, recorreu-se aos testes estatísticos de Kaiser-Meyer-Olkin (KMO) e de esfericidade de Bartlett, o que permite identificar a existência de correlaçōes lineares significativas entre os itens, condição "sine-qua-non" para a realização adequada da análise fatorial confirmatória. $\mathrm{O}$ valor do teste de KMO foi equivalente a 0,930 e o teste de esfericidade de Bartlett $\chi^{2}{ }_{(435)}=17003,867(\mathrm{p}<0,001)$, apontando para a legitimidade da realização da análise fatorial.

Mediante a realização da análise fatorial confirmatória com rotação ortogonal, de acordo com critério de normalização de Kaiser, foram encontrados oito fatores de motivação com "eigenvalues" superior a uma unidade, que contribuem para explicar conjuntamente por volta de $67 \%$ da variância total. As informações dos fatores extraídos e das respectivas proporçôes de variância explicada podem ser observadas na TABELA 2.

TABELA 2 - Análise fatorial exploratória do Participation Motivation Questionnaire (PMQ) traduzido para o idioma português administrado em atletas-jovens do Estado do Paraná, Brasil.

\begin{tabular}{lccc}
\hline & & \multicolumn{2}{c}{ Proporçáo de variância explicada (\%) } \\
\cline { 3 - 4 } Fatores extraídos & "Eigenvalues" & Individual & Acumulada \\
\hline Fator 1 & 11,021 & 33,67 & 33,67 \\
Fator 2 & 6,298 & 7,23 & 40,90 \\
Fator 3 & 3,936 & 6,90 & 47,80 \\
Fator 4 & 2,916 & 5,45 & 53,25 \\
Fator 5 & 1,973 & 4,01 & 57,26 \\
Fator 6 & 1,486 & 3,87 & 61,13 \\
Fator 7 & 1,294 & 3,43 & 64,56 \\
Fator 8 & 1,157 & 2,92 & 67,48 \\
\hline
\end{tabular}

Após a extração dos oito fatores de motivação identificou-se a estrutura fatorial do $P M Q$ na amostra de atletas-jovens selecionada no estudo. Neste caso, considerando que nenhum dos itens apresentou carga fatorial inferior a 0,40 ou estiveram representados em mais de um fator, todos os 30 itens foram contemplados na estrutura fatorial do $P M Q$ traduzido para o idioma português. A consistência interna de cada fator foi analisada mediante a estimativa do alfa de Cronbach $(\alpha)$. A definição da estrutura fatorial encontra-se exposta na TABELA 3. 
TABELA 3 - Estrutura fatorial do Participation Motivation Questionnaire (PMQ) traduzido para o idioma português administrado em atletas-jovens do Estado do Paraná, Brasil.

\begin{tabular}{lcc}
\hline Fatores de motivaçáo / itens & Peso fatorial & Alfa de Cronbach \\
\hline Fator 1 - Reconhecimento Social & & \\
25. Ser conhecido & 0,816 & \\
28. Ser reconhecido e ter prestígio & 0,813 & \\
21. Ter a sensação de ser importante & 0,782 & 0,827 \\
14. Receber prêmios & 0,744 & \\
19. Pretexto para sair de casa & 0,730 & \\
3. Ganhar dos adversários & 0,712 & \\
12. Fazer alguma coisa em que é bom & 0,701 & \\
\hline
\end{tabular}

\section{Fator 2 - Atividade de Grupo}

27. Satisfazer treinador/professor

0,805

18. Desenvolver o espírito de equipe

0,790

0,790

22. Pertencer a um grupo

0,771

8. Trabalhar em equipe

0,753

\section{Fator 3 - Aptidáo Física}

6. Manter a forma física

0,828

24. Estar em boas condições físicas $\quad 0,827$

15. Fazer exercício físico $\quad 0,803$

17. Ter ação $\quad 0,755$

\section{Fator 4 - Emoçáo}

7. Procurar emoçóes fortes

0,749

13. Controlar tensôes

0,710

0,744

4. Liberar energia

0,682

\section{Fator 5 - Competiçáo}
20. Competir
0,793

0,722

26. Enfrentar desafios

0,764

\section{Fator 6 - Competência Técnica}

10. Aprender novas habilidades

0,776

23. Atingir nível esportivo mais elevado

0,750

0,693

1. Melhorar as habilidades esportivas

0,701

\section{Fator 7 - Afiliação}
2. Estar com os amigos
0,873
11. Fazer novas amizades
0,842
0,640
9. Ser influenciado pela família e amigos
0,797

\section{Fator 8 - Diversáo}

$\begin{array}{ll}\text { 30. Utilizar instalações e equipamentos esportivos } & 0,804 \\ \text { 5. Viajar } & 0,726 \\ \text { 16. Ter alguma coisa para fazer } & 0,666 \\ \text { 29. Divertir } & 0,661\end{array}$


O fator 1 foi composto pela maior quantidade de itens. Os sete itens que compõe este fator apresentaram saturação individual entre 0,816 (Ser conhecido) e 0,701 (Fazer algo em que é bom). O valor calculado "eigenvalue" foi de 11,021, proporção de variância explicada de 33,67\% e índice de consistência interna de 0,827 . A estrutura fatorial encontrada sugere denominar este fator de "Reconhecimento Social".

Quatro itens representaram o fator 2, com diferenças na saturação individual extremas bastante discretas: entre 0,805 (Satisfazer treinador/professor) e 0,753 (Trabalhar em equipe). O valor calculado "eigenvalue" reduziu para 6,298 , por consequência a proporção de variância explicada para 7,23\%. No entanto, o índice de consistência interna se manteve elevado $(0,790)$. Em razão dos itens reunidos por este fator, parece inequívoca a denominação de "Atividade em Grupo".

$O$ fator 3 também reuniu quatro itens e recebeu a denominação de "Aptidão Física". Apresentou saturação entre 0,828 (Manter a forma física) e 0,755 (Ter ação), valor calculado de "eigenvalue" de 3,936, explicando 6,90\% da variância total. $\mathrm{O}$ índice de consistência interna foi equivalente a 0,753 .

O fator 4 concentrou três itens que, em comparação com os demais fatores, apresentou as menores saturações. O item 7 (Procurar emoçóes fortes) apresentou saturação de 0,749 , enquanto o item 4 (Liberar energia) apresentou saturação de 0,682. O valor calculado "eigenvalue" foi de 2,916, equivalente à explicação de 5,45\% da variância total, com índice de consistência interna de 0,744. Este fator recebeu a denominação de "Emoção".

\section{Discussão}

A efetivação das etapas do processo de tradução do instrumento não apresentou maiores dificuldades devido à metodologia adotada e à estrutura simples e objetiva de formulação dos itens do $P M Q$. A tradução inicial realizada pelos dois tradutores foi pouco modificada nas etapas subsequentes. A retrotradução, quando comparada ao instrumento original, apresentou discretas discrepâncias, resultantes de ajustes realizados para atender especificidades de determinados itens. A análise das equivalências semântica, idiomática, cultural e conceitual, equivalente a adaptação transcultural, como a etapa de tradução, indicou que o instrumento foi de fácil tradução.

A análise das equivalências mostrou que os domínios do $P M Q$ são apropriados e os atributos
Com dois itens reunidos em sua estrutura e com saturação de 0,793 (Competir) e 0,764 (Enfrentar desafios), o fator 5 recebeu a denominação "Competição". O valor calculado de "eigenvalue" foi de 1,973, equivalente a uma proporção de variância explica de 4,01\%. O índice de consistência interna deste fator correspondeu a um alfa de Cronbach de 0,722.

O fator 6 foi formado por três itens e apresentou uma estrutura que indica a denominação "Competência Técnica”. As saturações individuais variaram de 0,776 (Aprender novas habilidades) a 0,701 (Melhorar as habilidades esportivas). Este fator apresentou valor calculado de "eigenvalue" de 1,486, explicando $3,87 \%$ da variância total, com índice de consistência interna de 0,693.

Com uma estrutura que apontou a denominação "Afiliação", o fator 7 também reuniu três itens com saturações de 0,873 (Estar com os amigos) a 0,797 (Ser influenciado pela família e amigos). O valor calculado "eigenvalue" foi de 1,294 com capacidade explicativa da variância total de 3,43\%. O índice de consistência interna apresentou magnitude de 0,640.

Agregando quatro itens com a mais elevada amplitude de variação entre as saturações individuais, o fator 8 foi denominado de "Diversão". A saturação de seus itens variou de 0,804 (Utilizar instalaçóes e equipamentos esportivos) a 0,661 (Divertir). O valor calculado de "eigenvalue" foi bastante próximo de uma unidade $(1,157)$, o que correspondeu a uma capacidade explicativa de $2,92 \%$ da variância total. $\mathrm{O}$ índice de consistência interna foi o mais baixo entre os fatores extraídos no estudo $(0,543)$.

utilizados na versão original do instrumento são igualmente válido para a cultura-alvo, o que atende a equivalência cultural. A equivalência conceitual indicou que poucos itens necessitaram de ajustes. Os itens puderam ser considerados de maneira semelhante ao formato original, indicando, mais uma vez, que a estrutura de formulação do $P M Q$ foi bem elaborada. No que se refere à equivalência idiomática, a versão traduzida mostrou que $80 \%$ dos itens foram avaliados como "inalterado" e os demais como "pouco alterado" entre as versões original e retrotraduzida do instrumento. Nenhum membro do comitê de análise considerou algum item como "pouco alterado", quando da comparação entre as versões dos instrumentos original, traduzido e retrotraduzido. 
Quanto à estrutura fatorial do $P M Q$ traduzido e adaptado no presente estudo para o idioma português, constatou-se disposição semelhante a encontrada na versão original proposta por GILL et al. ${ }^{7}$, também sendo extraídos oito fatores de motivação. Porém, observou-se que a consistência interna de cada fator de motivação, apontada pelos valores alfa de Cronbach, de modo geral, foram mais elevados na estrutura fatorial do $P M Q$ traduzido para o idioma português em comparação com a versão original TABELA 4. Também, a amplitude de variação entre os escores mais elevado $(0,827)$ e mais baixo $(0,543)$ é inferior a apresentada pela versão original do $P M Q(0,78$ e 0,30 , respectivamente), o que sugere maior equilíbrio entre os fatores de motivação da versão traduzida para o idioma português. Prováveis justificativas para esses achados possam estar associadas às diferenças nas dimensões da escala de pontuação utilizada em ambas as versóes do $P M Q$ e às características das amostras selecionadas em um e outro estudo. Na versão original foi empregada escala de medida de três pontos, enquanto na versão traduzida do $P M Q$ utilizou-se de escala de medida de cinco pontos; logo, com maior capacidade discriminatória em suas respostas. No que se refere às características das amostras selecionadas em um e outro estudo, originalmente o $P M Q$ foi aplicado em jovens engajados em programas de férias de verão envolvendo esporte em um contexto de lazer (Iowa Summer Sports School), enquanto no presente estudo os jovens se encontravam em contexto de elevado nível de competição, participando da etapa final dos Jogos da Juventude do Paraná, principal competição estadual para atletas-jovens com $\leq 18$ anos. Portanto, é possível que os contextos em que ambos os estudos foram realizados possam ter definido diferenças quanto ao perfil de interesse pela prática de esporte.

TABELA 4 - Estrutura fatorial do Participation Motivation Questionnaire (PMQ) identificada no estudo original e na versão traduzida para o idioma português.

\begin{tabular}{|c|c|c|c|c|c|}
\hline \multicolumn{3}{|c|}{ Versão original } & \multicolumn{3}{|c|}{ Versão traduzida para o idioma português } \\
\hline Fatores de motivação & Itens & Alfa de Conbach & Fatores de motivação & Itens & Alfa de Conbach \\
\hline "Achievement/Status" & 6 & 0,76 & Reconhecimento Social & 7 & 0,827 \\
\hline "Team Oriented Reasons" & 3 & 0,78 & Atividade de Grupo & 4 & 0,790 \\
\hline "Fitness" & 3 & 0,75 & Aptidão Física & 4 & 0,753 \\
\hline "Energy Release" & 5 & 0,65 & Emoção & 3 & 0,744 \\
\hline \multirow[t]{2}{*}{ "Miscellaneous Reasons" } & 3 & 0,49 & & & \\
\hline & & & Competição & 2 & 0,722 \\
\hline "Skill Development" & 3 & 0,44 & Competência Técnica & 3 & 0,693 \\
\hline "Friendship Items" & 2 & 0,30 & Afiliação & 3 & 0,640 \\
\hline "Fun" & 3 & 0,55 & Diversão & 4 & 0,543 \\
\hline
\end{tabular}

O primeiro fator de motivação da versão traduzida, denominado "Reconhecimento Social", procura atender aspectos de motivação vinculados à aprovação social, à busca de prestígio, à superação pessoal e à auto-realização. Em comparação com a versão original do $P M Q$, definido pela expressão "Achievement/Status", este fator de motivação passou a reunir sete itens ao invés dos seis propostos no estudo de GiLl et al.7. Neste caso, a estrutura fatorial indicou a adição do item "Pretexto para sair de casa", que originalmente atendia o fator de motivação "Energy Release". Interessante observar que, além de ser identificado em todas as demais versōes traduzidas do $P M Q^{9-16}$, mesmo demonstrando diferentes composições, em todas as versões foi o fator de motivação que reuniu a mais eleva quantidade de itens.

O fator de motivação identificado como "Atividade de Grupo", também pode ser considerado como tendo vínculo com motivos associados à aprovação social. Também comporta um item a mais que a versão original do $P M Q$, o que no idioma inglês foi denominado de "Team-Oriented Reasons". O item "Satisfazer treinador/professor" removido para este fator de motivação, originalmente se encontrava no fator de motivação denominado "Miscellaneous Reasons". Na versão traduzida do $P M Q$ o fator de motivação "Aptidão Física" relaciona-se com motivos de ordem fisiológica e de condicionamento fisco para a prática de esporte, podendo atender critérios 
vinculados à saúde. Além dos três itens contemplados na versão em idioma inglês, denominada "Fitness", este fator de motivação abrigou o item "Ter ação" que, originalmente, atendeu ao fator de motivação "Fun".

Em comparação com a versão original do $P M Q$, os fatores de motivação "Emoção" e "Diversão" foram os que apresentaram as mais acentuadas diferenças na estrutura fatorial de seus componentes. No entanto, ambos os fatores de motivação abrigam importantes componentes intrínsecos potencialmente relacionados ao impulso da própria vontade, ou seja, o que induz alguém voluntariamente a fazer algo com desfrute. Na versão original o equivalente fator de motivação "Emoção", denominado "Energy Release", abrigou cinco itens, enquanto na versão traduzida a analise fatorial identificou apenas três itens, ainda assim, somente dois deles coincidentes em ambas as versōes do PMQ: "Controlar tensóes" e "Liberar energia". O terceiro item identificado neste fator de motivação na versão traduzida foi "Procurar emoções fortes" que, na versão em idioma inglês, é contemplado no fator de motivação "Fun".

No que se refere ao fator de motivação "Diversão", que na versão original do $P M Q$ recebeu a denominação de "Fun" e engloba três itens, passou a reunir na versão traduzida para o idioma português quatro itens. No entanto, apenas um deles, "Divertir", pertence ao agrupamento original. Neste caso, para compor a nova estrutura fatorial, o fator de motivação "Diversão" recebeu dois itens originariamente pertencente ao fator de motivação "Energy Release": "Ter algo para fazer" e "Viajar", e um item presente na versão original no fator de motivação "Miscellaneous Reasons": "Utilizar instalaçôes e equipamentos esportivos".

Provavelmente, diferentes concepções dos jovens selecionados em ambos os estudos quanto aos componentes intrínsecos relacionados à "Emoção" e à "Diversão" possam justificar estruturas fatoriais divergentes entre as versões original e traduzida para o idioma português. Evidência desta possibilidade é o fato dos fatores de motivação presentes na versão original "Energy Release" e "Miscellaneous Reasons" nem sempre se repetirem em versões traduzidas para outros idiomas do $P M Q^{11-13,16}$, tendo seus itens excluídos da estrutura fatorial ou agrupados em outros fatores de motivação, como foi o caso da versão traduzida para o idioma português.
Fator de motivação não relacionado na versão original; porém, com importante peso fatorial na versão traduzida do $P M Q$ foi o que recebeu a denominação de "Competição". Este fator resultou da agregação de dois itens associados ao enfrentamento de desafios e à exposição de riscos. No entanto, na versão original do $P M Q$ ambos os itens foram excluídos de sua estrutura fatorial por estarem representados em mais de um fator; logo, neste caso, passaram a ser utilizados tão-somente como questôes-placebo. Mais uma vez, existe possibilidade das diferentes concepçōes quanto às ações de "Competir" e "Enfrentar desafios", apresentadas pelos jovens reunidos no estudo de GILL et al. ${ }^{7}$ e no presente estudo, terem contribuído para que diferentes estruturas fatoriais pudessem ser identificadas. $O$ fator de motivação "Competência Técnica" abriga três itens em que o jovem atleta justifica a prática de esporte mediante metas de auto-realização associadas ao domínio e ao aperfeiçoamento das habilidades esportivas. Na versão original do $P M Q$ este fator de motivação recebeu a denominação de "Skill Development" e reuniu os mesmos três itens da versão traduzida para o idioma português.

O fator de motivação "Afiliação" concentrou três itens voltados à aprovação social de extrema importância para a percepção de amizade com os pares. $\mathrm{Na}$ constituição desse fator de motivação, além dos dois itens também contemplados na versão original do $P M Q$, mediante o fator de motivação denominado "Friendship Itens", o item "Influência da famílialamigos", anteriormente presente no fator de motivação "Miscellaneous Reasons", também foi fatorizado em sua estrutura.

Concluindo, o instrumento $P M Q$ traduzido e adaptado para o idioma português alcançou bom desempenho psicométrico frente à amostra do presente estudo, apresentando elevados coeficientes alfa de Cronbach calculados para os fatores de motivação gerados. A análise fatorial confirmatória com rotação Varimax possibilitou a geração de oito fatores de motivação que, em conjunto, podem explicar proporção de variância próxima de $67 \%$. A solução fatorial gerada foi similar a apresentada originalmente no estudo de GiLl et al. ${ }^{7}$, e da maioria dos estudos publicados utilizando o mesmo delineamento experimental. Desta maneira, a versão do PMQ disponibilizada no presente estudo mostrou-se promissora para utilização em futuras intervenções com objetivo de analisar os motivos para a prática de esporte em atletas-jovens brasileiros. 


\begin{abstract}
Participation motivation questionnaire: translation and validation for use in Brazilian young athletes

The objectives of this study were to translate for the Portuguese language, describe the cross-cultural adaptation and identify the psychometric properties to the Brazilian young athletes of the Participation Motivation Questionnaire (PMO). The original questionnaire was translated following international recommendations. Translated versions of the questionnaire were analyzes by a committee of experts. The committee used semantic, idiomatic, cultural and conceptual equivalences as criteria of analysis. The final version of the translated questionnaire was administered in a sample of 1517 young athletes (714 girls and 803 boys) aged 12 to 18 years-old. To identify the psychometric properties confirmatory factorial analysis with varimax rotation were completed. Cronbach's alpha coefficient was used to assess the internal consistency of each factor of the PMO associated to motivation for the practice of sport. After minor changes identified in the translation process, the committee of experts considered that the Portuguese version of the PMO showed semantic, idiomatic, cultural and conceptual equivalences. The factorial analysis confirmed the structure of eight factors originally proposed, explaining 67\% of the total variance and presenting reasonable values of internal consistency. The Cronbach-alpha ranged from 0.543 to 0.827 . In conclusion, the translation, cross-cultural adaptation and psychometric qualities of the PMO were satisfactory, thus enabling its application in future studies in Brazil.
\end{abstract}

KEY WORDS: PMQ; Questionnaire; Psychometrics; Sports training; Adolescents; Brazil.

\title{
Referências
}

1. Ryan RM, Deci EL. Self-Determination Theory and the facilitation of intrinsic motivation, social development, and well-being. Am Psychol. 2000;55:68-78.

2. Ntoumanis N. A self-determination approach to the understanding of motivation in physical education. Br J Educ Psychol. 2001;71:225-42.

3. Gill DL, Williams L. Psychological dynamics of sport and exercise. 3rd ed. Champaign: Human Kinetics; 2008.

4. Roberts GC, Treasure DC, Balagué G. Achievement goals in sport: the development and validation of the Perception of Success Questionnaire. J Sports Sci. 1998;16:337-47.

5. Newton M, Duda JL, Yin Z. Examination of the psychometric properties of the Perceived Motivational Climate is Sport Questionnaire-2 in a simple of female athletes. J Sports Sci. 2000;18:275-90.

6. Jackson SA, Eklund RC. Assessing flow in physical activity: the Flow State Scale-2 and Dispositional Flow Scale-2. J Sport Exerc Psychol. 2002;24:133-50.

7. Gill DL, Gross JB, Huddleston S. Participation motivation in youth sports. Int J Sport Psychol. 1983;14:1-14.

8. Dwyer JJM. Internal structure of participation motives questionnaire completed by undergraduates. Psychol Rep.1992;70:283-90.

9. Serpa S. Motivação para a prática desportiva: validação preliminar do questionário de motivação para as actividades desportivas (QMAD). In: Sobral F, Marques A. FACDEX: Desenvolvimento somato-motor e factores de excelência desportiva na população escolar portuguesa. Lisboa: Ministério da Educação; 1992. p.89-97.

10. Buonamano A, Cei A, Mussino A. Participation motivation in Italian Youth Sport. The Sports Psychology. 1995;9:265-81.

11. Shang CM. A study on the motivation of middle school students in participating in track and field competitions. Chinese Electronic Periodical Service.1997;22:375-86.

12. Chadha NK, Kolt GS. Intergenerational relationship building through participation in physical activity. Indian J Gerontol. 2004;18:318-47.

13. Doulias E, Kosmidou E, Paulogiannis O, Patsiaouras A. Examination of participation motives in folk dance groups. Inquiries Sport Phys Educ. 2005;3:107-12.

14. Hu WY, Wei Y. Effects on goal orientations and participation motives to university students' physical education and sport. Zhejianq Sport Sci. 2005;4:41-5.

15. Thiborg J. Fotbollsspelares personlighet, motiv och moral i idrotten. Sektionen Lek, Fritid och Hälsa: Högskolan i Malmö, Sweden. 2005.

146 • Rev Bras Educ Fís Esporte, (São Paulo) 2013 Jan-Mar;27(1):137-48 
16. Gürbuz B, Altyntas A, Asci F, Hülya A. Participation motives of 9-15 years old Turkish soccer players. J Sports Sci Med. 2007;10 Suppl:88-91.

17. Fonseca AM, Maia JA. Análise factorial confirmatória à versão portuguesa do Participation Motivation Questionnaire. In: Fonseca AM. A FCDEF-UP e a psicologia do desporto: estudos sobre motivação. Porto: Faculdade de Ciências do Desporto e Educação Física,Universidade do Porto; 2001.

18. Gaya A, Cardoso M. Os fatores motivacionais para a prática desportiva e suas relações com o sexo, idade e níveis de desempenho desportivo. Rev Perfil. 1998;2:40-51.

19. Guillemin F, Bombardier C, Beaton D. Cross-cultural adaptation of health-related quality of life measures: literature review and proposed guidelines. J Clin Epidemiol. 1993;46:14-32.

ANEXO I - Participation Motivation Questionnaire (PMQ). Versão traduzida e adaptada para o idioma português.

Abaixo estão alguns motivos que podem levar as pessoas a praticarem esportes. Leia com atenção cada item e marque com "X" o quanto cada um desses motivos é importante atualmente para Você praticar sua modalidade esportivas.

\section{Eu pratico esportes para:}

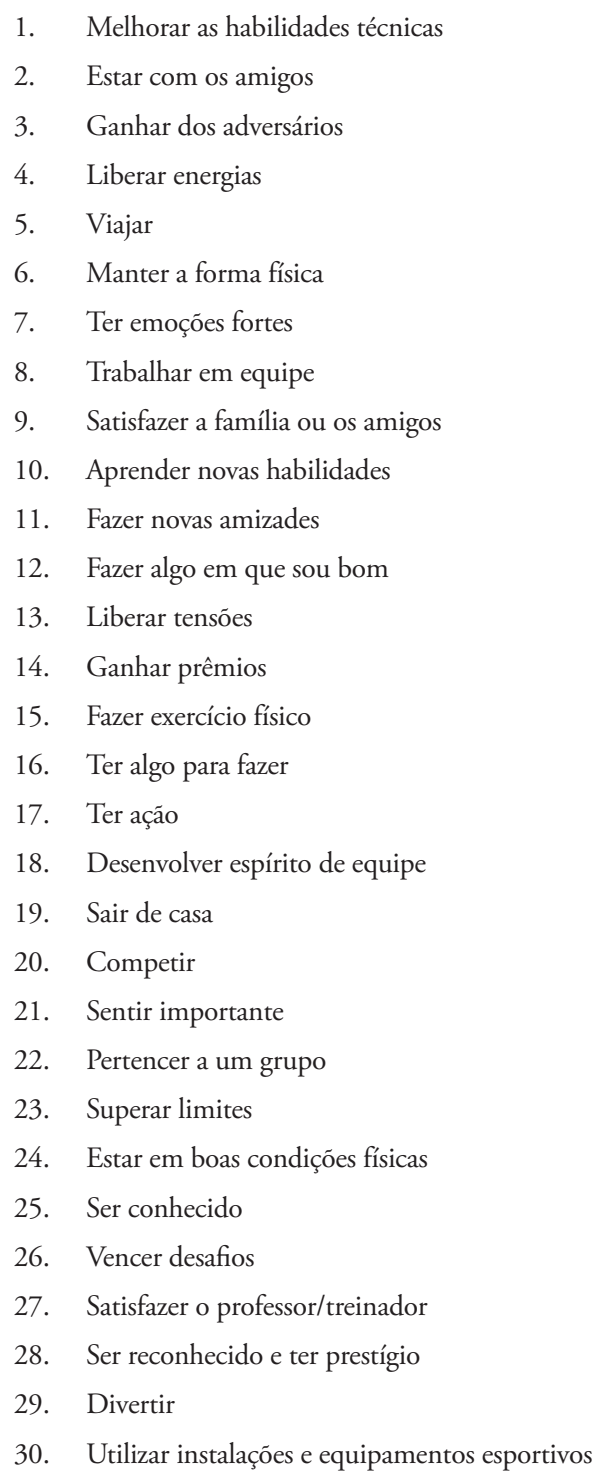

\begin{tabular}{ccccc}
$\begin{array}{c}\text { Nada } \\
\text { importante } \\
\downarrow\end{array}$ & & \multicolumn{2}{r}{ Muito } \\
$\downarrow$ & & & & $\downarrow$ \\
1 & 2 & 3 & 4 & 5 \\
1 & 2 & 3 & 4 & 5 \\
1 & 2 & 3 & 4 & 5 \\
1 & 2 & 3 & 4 & 5 \\
1 & 2 & 3 & 4 & 5 \\
1 & 2 & 3 & 4 & 5 \\
1 & 2 & 3 & 4 & 5 \\
1 & 2 & 3 & 4 & 5 \\
1 & 2 & 3 & 4 & 5 \\
1 & 2 & 3 & 4 & 5 \\
1 & 2 & 3 & 4 & 5 \\
1 & 2 & 3 & 4 & 5 \\
1 & 2 & 3 & 4 & 5 \\
1 & 2 & 3 & 4 & 5 \\
1 & 2 & 3 & 4 & 5 \\
1 & 2 & 3 & 4 & 5 \\
1 & 2 & 3 & 4 & 5 \\
1 & 2 & 3 & 4 & 5 \\
1 & 2 & 3 & 4 & 5 \\
1 & 2 & 3 & 4 & 5 \\
1 & 2 & 3 & 4 & 5 \\
1 & 2 & 3 & 4 & 5 \\
1 & 2 & 3 & 4 & 5 \\
1 & 2 & 3 & 4 & 5 \\
1 & 2 & 3 & 4 & 5 \\
1 & 2 & 3 & 4 & 5 \\
1 & 2 & 3 & 4 & 5 \\
1 & 2 & 3 & 4 & 5 \\
1 & 2 & 3 & 4 & 5 \\
1 & 2 & 3 & 4 & 5
\end{tabular}




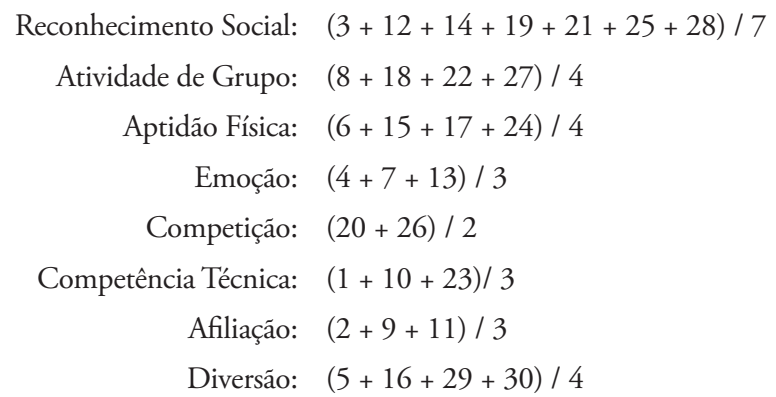

\begin{tabular}{r|l} 
ENDEREÇo & \\
Dartagnan Pinto Guedes & \\
Londrina - PR - BRASIL & Recebido para publicação: 16/08/2011 \\
1arta@serconte: 09/03/2012 \\
2a. Revisão: 28/05/2012 \\
& Aceito: 14/06/2012
\end{tabular}

148 • Rev Bras Educ Fís Esporte, (São Paulo) 2013 Jan-Mar;27(1):137-48 